\title{
IPTEKS PERLAKUAN AKUNTANSI TERHADAP PENGUKURAN ASET TETAP PADA KANTOR LURAH KLEAK
}

\author{
Reinhard Valen $\mathrm{Ipu}^{1}$, Sherly Pinatik ${ }^{2}$ \\ ${ }^{1,2}$ Jurusan Akuntansi, Fakultas Ekonomi dan Bisnis, Universitas Sam Ratulangi, Jl. Kampus Bahu, Kota \\ Manado, 95115, Indonesia \\ email : rheinhardipu@gmail.com
}

\begin{abstract}
Fixed assets are tangible assets owned by the company or agency in question not for sale, but to assist the operational activities of an agency and have a useful life of more than one year. The kleak village office has several supporting factors in conducting operational activities, one of which in the form of office equipment. This study aims to determine wherher the village office has measured fixed assets based on applicable financial accounting standards. Based on the data that the author obtained it can seen that the village office has not measured fixed assets in accordance with PSAK No. 16.
\end{abstract}

Keywords : Measurement of fixed assets, PSAK No. 16.

\section{PENDAHULUAN}

Akuntansi merupakan suatu ilmu yang tidak dapat di pisahkan dalam kegiatan operasional intansi pemerintahan maupun perusahan. Pihak instansi membutuhkan data akuntansi sebagai sumber informasi agar operasional instansi dapat berjalan efektif dan efisien. Data akuntansi yang dibutuhkan pihak instansi harus bersifat akurat dan dapat di percaya agar dapat meningkatkan efektivitas instansi tersebut. Akuntansi menjadi sarana dalam pengegelolahan aset tetap agar sesuai dengan kebutuhan pihak yang berkepentingan dalam bidang tersebut. Dalam pengelolahan, pengawasan harta kekayaan perusahaan diperlukan dasar-dasar proses akuntansi saat aset tersebut diperoleh sampai aset tersebut dihapuskan. Pengungkapan aset tetap pada penyajian laporan keuangan harus dijelaskan seara rinci. Ketidak lengkapan penyajian laporan keuangan yang ada membuat pemakai atau pengguna kebingunan.

Pengguna akan menilai suatu perusahaan atau instansi tersebut bersuaha menyembunyikan informasi yang sebenarnya dan kualitas lapornan keuangan menjadi tidak akurat dan tidak dapat dipercaya. Untuk itu penyajian dan pengungkapan aset tetap harus berdasarkan pada Standar Akuntansi Keuangan yang berlaku. Pengukuran aset tetap pada suatu instansi dapat dilakukan dengan cara membandingkan harga serta nilai aset yang ada di laporan keuangan dengan harga serta nilai aset yang ada di pasaran saat ini apakah nilai aset tersebut sudah mengalami penurunan dan apakah aset tersebut perlu dilakukan penyesuaian nilai aset dalam laporan keuangan.

\section{TINJAUAN PUSTAKA}

Pengertian akuntansi. A Statement of Basic Accounting Theory (ASOBAT) (Syakur, 2015:2) mengungkapkan bahwa akuntansi merupakan proses penyampaian informasi untuk mempertimbankan alternatif-alternatif dalam mengambil sebuah kesimpulan. Sedangkan menurut Mardiasmo (2014: 1), akuntansi adalah suatu seni dalam pelaporan transaksi-transaksi aktifitas keuangan. Secara umum akuntansi adalah proses mengidentifikasi, mengukur, mengklasifikasi, dan mengikthisar sebuah transaksi keuangan 
atau proses yang dapat menghasilkan data yang bersifat keuangan yang yang dapat digunakan dalam membuat keputusan. Akuntansi adalah laporan yang berisi catatan informasi keuangan yang akan disampaikan kepada pihak atau pengguna informasi dalam menunjang kinerja serta kondisi keuangan perusahaan (Hery 2015:6). Akuntansi keuangan (financial accounting) adalah suatu proses yang digunakan oleh pihak internal maupun external yang didalamnya berisi laporan keuangan suatu entitas.laporan keuangan adalah keluaran utama akuntansi keuangan (Giri, 2012: 4).

Aset Tetap. Aset tetap berwujud merupakan harta kekayaan yang, relative permanen, dan digunakan lebih dari satu tahun sebagai operasi regular. Aset tetap berwujud dibeli dengan tujuan untuk tidak dijual kembali. Aset tetap berwujud terdiri dari atas tanah, bangunan atau gedung, mesin-mesin. Perabot dan peralatan kantor. Aset tetap berwujud yang umurnya tidak terbatas misalnya tanah, disajikan berdasarkan harga perolehan dikurnagi dengan akumulasi ini disebut nilai buku atau aset tetap berwujud bersih (Wahyudiono, 2014:25). Aset tetap yang dimiliki instansi tidak hanya sekedar digunakan manfaatnya tetapi instansi tersebut harus memiliki kontrol dan pengawasan yang baik atas aset tetap mulai dari pengadaan dan pemakaian sampai berakhirnya masa manfaat aset tersebut ( Balak, 2016).

Klasifikasi Aset Tetap. Dalam kegiatan operasional perusahaan memiliki jenis aset tetap yang berbeda, yaitu :

1. Di pandang dari substansi aset tetap terdiri dari: lahan, gudung dan lain-lain dikategorikan sebagai aset berwujud. Hak cipta merupakan contoh dari aset tidak berwujud. Dalam pengambilan keputusan sistem akuntasi tradisional dilaksanakan lebih sulit untuk memastikan peran informatif dari jenis asaet dalam pertumbuhan yang berkelanjutan (Brahim,2012).

2. Dari sudut pandang penyusutan aset tetap terdiri dari :

1) Aset tetap yang sudah habis masa kegunaanya diganti dengan aset yang baru dan sejenis dengan aset.

2) Undeperciated plant Assets (Aset tetap yang tidak disusutkan) yaitu aset tetap masa penggunaannya tidak pernah habis. Atuau selalu berlaku.

Pengukuran Aset Tetap. Aset tetap yang pada awalnya dicatat sebesar harga perolehan agar memenuhi kualifikasi dari suatu aset (IAI, 2009 : 16.4).

\section{Penelitian Terdahulu}

1. Penelitian yang dilakukan Ratag (2013) menunjukkan bahwa PT. Bank Sulut telah sesuai dengan PSAK No. 16.

2. Mustamin, Fitrah. 2013. Analisis Pengakuan aset, pengukuran dan pelaporan aset tetap.

3. Penelitian yang dilakukan Eleanor (2016) tentang evaluasi penerapan perlakuan akuntansi terhadap aktiva tetap berdasarkan PSAK No.16 Tahun 2011 pada PT. Nichindo Manado Suisan.

\section{METODE DAN TEKNIK PENERAPAN IPTEKS}

\subsection{Metode Penerapan Ipteks}

Menerapkan perlakuan akuntansi terhadap pengukuran aset tetap berdasarkan standar yang disarankan dalam PSAK NO. 16

\subsection{Teknik Penerapan Ipteks}

Pngukuran aset tetap yang didasarkan pada Standar Akuntansi keuangan yang berlaku. yaitu penurunan signifikan nilai pasar, peningkatan suku bunga pasar, tingkat imbalan pasar investasi, jumlah tercatat neto entitas melebihi jumlah kapitalisasi pasarnya, bukti keusangan dan kerusakan fisik aset. 


\section{PEMBAHASAN}

\subsection{Gambaran Objek Penerapan Ipteks}

Keluhan kleak merupakan salah satu kelurahan yang termasuk dikecamatan Malalayang dari Sembilan kelurahan yang ada. Kelurahan kleak merupakan proses pemekaran dari desa Bahu kecamatan sario pada tahun 1978 yang waktu itu dibagi menjadi desa bahu dan desa kleak dan sampai saat ini kelurahan kleak dibagi menjadi enam lingkungan.

\subsection{Pembahasan}

Berdasarkan data yang penulis peroleh dapat dilihat bahwa pihak kantor kelurahan belum melakukan pengukeran aset tetap sesuai PSAK No. 16. Hal tersebut dapat dilihat dari nilai buku masing-masing aset yang di beli dari tahun 2012 yang masi memiliki masa manfaat sampai dengan tahun 2018. Pihak kantor kelurahan seharusnya setiap tahun melakukan pengujian terhadap penurunan nilai aset (membandingkan apakah nilai aset yang dicatat lebih besarkkecil dari nilai yang ada di pasaran)

\section{KESIMPULAN DAN SARAN}

\subsection{Kesimpulan}

Pengukuran kembali aset tetap oleh pihak kantor kelurahan seharusnya setiap tahun melakukan pengujian terhadap penurunan nilai aset.

\subsection{Saran}

Pentingnya pengukuran aset tetap yang baik dari pihak kantor kelurahan, yang dimaksudkan adalah pihak kantor kelurahan harus melakukan pengujian terhadap penurunan nilai aset untuk setiap tahunnya agar penyajian laporan keuangan tentang aset tetap dapat $\mathrm{d}$ sajikan dengan baik dan aktivitas kelurahan dapat berjalan dengan efektif dan efisien.

\section{DAFTAR PUSTAKA}

Balak, Indra. 2016. Perlakuan Akuntasi Capital expenditure dan revenue expenditure pada PT. Maesa Nugraha Manado. Jurnal Emba Vol 4 Hal 19.

Brahim, Houneida. 2012. The relevance of the information about intangibles: some determinants. International journal of accounting and financial reporting Vol 2.

Eleanor, 2016. Evaluasi Penerapan Perlakuan Akuntansi terhadap Aktiva Tetap Berdasarkan PSAK No.16 Tahun 2011pada PT. Nichindo Manado Suisan. Universitas Sam Ratulangi Manado. Fakultas Ekonomi dan Bisnis

Giri, Efraim Ferdinan. 2012. Akuntansi Keuangan Menengah 1. UPP STIM YKPN. Yogyakarta.

Hery. 2015. Analisis laporan keuangan pendekatan rasio keuangan. Center for Academic Publishing Service (CAPS). Yogyakarta.

Ikatan Akuntan Indonesia (IAI). 2015. Pernyataan Standar Akuntansi Keuangan No. 16. Jakarta

Ikatan Akuntan Indonesia (IAI). 2009. Pernyataan Standar Akuntansi Keuangan No. 58. Jakarta

Mardiasmo. 2014. Akuntansi Keuangan Dasar 1. Cetakan k Giri, Efraim Ferdinan. 2012. Akuntansi Keuangan Menengah 1. UPP STIM YKPN. Yogyakarta.e Empat. BPFE, yogyakarta.

Mustamin, Fitrah. 2013. Analisis Pengakuan, Pengukuran dan Pelaporan Aktiva Tetap Berdasarkan PSAK No. 16. Universitas Sam Ratulangi Manado. Jurnal EMBA ISSN 2303-1174. Vol. 1. 
Ratag, Suryani Miyoko, 2013. Perlakuan Akuntansi Capital Expenditure Dan Revenue Expenditure Pada PT. Bank SULUT. Universitas Sam Ratulangi Manado. Jurnal EMBA ISS 2303-1174. Vol. 3.

Syakur S, Ahmad. 2015. Intermediate Accounting. Pembuka Cakrawala. Jakarta.

Wahyudiono, Bambang. 2014. Mudah membaca Laporan Keungan. Jakarta: Raih Asa Sukses (Penebar Swadaya Grup). 